\title{
Complementary use of GCXGC-TOF-MS and statistics for differentiation of variety in biosolid samples
}

\author{
Hubert Byliński ${ }^{1}$ D $\cdot$ Tomasz Dymerski $^{1}$ · Jacek Gębicki ${ }^{2}$ Jacek Namieśnik ${ }^{1}$
}

Received: 28 February 2018 / Accepted: 7 May 2018/ Published online: 9 August 2018

(C) The Author(s) 2018

\begin{abstract}
Formation of biosolid cakes, which are one of the main wastes generated in wastewater treatment plants, is connected with emission of many hazardous chemical compounds, including odoriferous ones. To optimize particular processes of biosolid cake processing, it is necessary to assess chemical composition of the gas mixtures containing the compounds released from the cakes. The paper proposes application of two-dimensional gas chromatography coupled with time-of-flight mass spectrometry (GCxGC-TOF-MS) to identification of the compounds released from four main types of biosolid cakes and to quantitative determination of the markers characteristic for particular types of cake. Based on the analysis of variance, the following compounds, which could be potential markers of the investigated biosolid cakes, were selected: 1-propanol, 2-hexanone, toluene, $o$-xylene, $p$-xylene, and organosulfur compounds (methanethiol, ethanethiol, dimethyl sulfide, dimethyl disulfide, and diethyl disulfide). Theoretical odour concentrations of four investigated types of biosolid cakes were determined, based on measured concentrations and olfactory thresholds of the aforementioned compounds. The highest concentration was revealed for a primary cake $\left(634 \mathrm{ou} / \mathrm{m}^{3}\right)$, whereas the lowest concentration was found for an excess cake $\left(136 \mathrm{ou} / \mathrm{m}^{3}\right)\left(\mathrm{ou} / \mathrm{m}^{3}\right.$ _odour unit per $\mathrm{m}^{3}$; one odour unit is equivalent to collective odour threshold of odorants mixture present in $1 \mathrm{~m}^{3}$ ). The proposed methodology allows preliminary evaluation of the odour nuisance markers connected with formation of the biosolid cakes, without a need for quantitative analysis of all determined compounds.
\end{abstract}

\section{Graphical abstract}

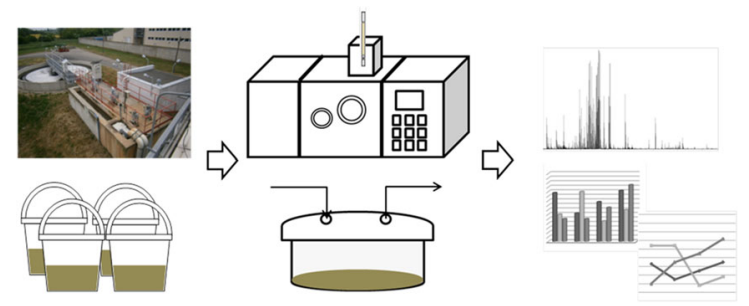

Keywords Gas chromatography · Mass spectroscopy · Odoriferous substances · Biosolid samples · Wastewater treatment plant

Hubert Byliński

hubert.bylinski@gmail.com

1 Department of Analytical Chemistry, Faculty of Chemistry, Gdańsk University of Technology, Gdańsk, Poland

2 Department of Chemical and Process Engineering, Faculty of Chemistry, Gdańsk University of Technology, Gdańsk, Poland

\section{Introduction}

Operation of wastewater treatment plants is accompanied by generation of biosolid cakes, which are the sources of numerous hazardous chemical compounds, including malodorous ones [1-3]. The substances released during processing of the biosolids are complex mixtures of volatile organic compounds, with a significant contribution of organosulfur compounds, aldehydes, ketones, esters, and 
alcohols $[4,5]$. Their content is strongly dependent on size of the city agglomeration and industrialization of the regions, from which sewage is collected as well as on a treatment technology employed. Selection of the optimum technology of biosolid cake processing should take into account changes in concentration level of particular chemical compounds. It is a very difficult task in case of the waste, including biosolids, generated in the wastewater treatment plants; the reason is variety in chemical composition of the material supplied [6].

The main unit operations, such as biosolid stabilization, composting, dewatering, drying, or thermal processing, are carried out in the wastewater treatment plants to limit negative environmental impact [7]. Execution of these processes is indispensable for further processing of the biosolid cakes; however, it does not ensure total removal of all potentially hazardous chemical and odoriferous compounds [8]. The investigations on the determination of the compounds released from the biosolid cakes show that their variety significantly hinders identification of those, which have the most negative influence on the environment. It is also difficult to point these compounds, which have the biggest impact on nuisance that affects the employees of the wastewater treatment plants and the residents of the areas neighbouring such municipal objects. That is why, it is necessary to elaborate a methodology of determination of the compounds released from the biosolid cakes, based on the instrumental tools available. This procedure should also utilize statistical and chemometric methods available. Significant optimization possibilities are created by statistical tests, which make it possible to define mutual correlation between investigated samples, including analysis of variance [9-12].

One of the technical solutions enabling measurement of emission of volatile odoriferous compounds, released from solid or liquid specimens surfaces (including the biosolid cakes), is application of the enclosure chambers [13]. In 1986, the Unites States of America Environmental Protection Agency (US EPA) issued a document regulating emission measurements using a flux hood chamber [14]. Its operation consists in: isolation of the investigated surface, blowing with high purity gas, and then measurement of the analytes using selected instrumental solution [15]. Chromatographic techniques, mainly gas chromatography coupled with mass spectrometry, are the most frequently used for determination of chemical composition of odoriferous gas mixtures. Popularity of this solution stems from the possibility of measurement of the components present at trace concentration level in the samples of various origin and composition [16, 17]. In the case of separation of complex mixtures of chemical compounds, one-dimensional chromatographic analysis can be insufficient for the identification of a wide array of the substances present in the samples. An alternative solution is two-dimensional gas chromatography coupled with time-of-flight mass spectrometry (GCxGC-TOF-MS), which is characterized by better resolution than the GC-MS technique $[18,19]$. It results from the fact that the components of investigated sample, which are present in a mobile phase, leave the first chromatographic column and then they are collected and fractionally dosed into the second column using a modulator (being central element of the GCxGC system). Both columns differ in polarity of the stationary phase, which allows an increase in selectivity [20, 21]. The GCxGC-MS technique provides the information about qualitative and quantitative composition of the investigated samples characterized by complex matrix composition [22]. Waste generated in the wastewater treatment plants, including the biosolid cakes, belongs to aforementioned type of the samples, and hence, selection of the GCxGC technique is fully justified.

The aim of performed investigation was an attempt to identify those chemical compounds released from four types of biosolid cakes, which could be their potential markers. Identification of the compounds enabling differentiation between particular types of biosolids was based on the results of qualitative analysis employing the GCxGC-TOF-MS technique and analysis of variance. Quantitative analysis of the compounds and their olfactory thresholds provided theoretical odour concentrations for four investigated types of biosolid cakes.

\section{Results and discussion}

\section{VOCs identified}

Using the GCxGC-TOF-MS system, it was possible to identify the volatile chemical compounds emitted from various biosolid samples produced in WWTPs. As an example, Table 1 lists the chemical compounds emitted from the primary sludge. It can be observed that dominant groups of volatile substances emitted from the biosolid samples are: aldehydes, ketones, sulfur compounds, and aromatic hydrocarbons. These groups of VOCs have previously been reported in the other studies [23-25]. However, in some cases, the chemical compounds belonging to different classes can have similar physicochemical properties and it causes a co-elution in the first retention time. As a result, it is not possible to separate all of the substances present in analysed samples. Application of twodimensional gas chromatography system allows obtaining full separation of determined compounds. It is a consequence of using two independent separation mechanisms based on volatility and polarity. 
Table 1 Chemical compounds emitted from primary sludge

\begin{tabular}{|c|c|c|c|}
\hline 1st RT/s & 2nd RT/s & Name of compounds & Similarity $^{\mathrm{a}}$ \\
\hline 270 & 1.46 & 2-Propenal & 876 \\
\hline 278 & 1.22 & Methanethiol & 881 \\
\hline 286 & 2.19 & Acetonitrile & 966 \\
\hline 286 & 1.74 & Ethanol & 939 \\
\hline 290 & 1.38 & 2-Propanone & 926 \\
\hline 290 & 1.46 & 2-Propenal & 875 \\
\hline 290 & 1.32 & Propanal & 894 \\
\hline 294 & 1.21 & Ethanethiol & 907 \\
\hline 302 & 1.33 & Dimethyl sulfide & 919 \\
\hline 310 & 2.31 & 1-Propanol & 937 \\
\hline 318 & 1.33 & Diethyl disulfide & 918 \\
\hline 326 & 1.66 & 2-Butanone & 946 \\
\hline 330 & 1.55 & Butanal & 952 \\
\hline 350 & 1.54 & 2-Ethylbutanal & 970 \\
\hline 370 & 1.66 & Benzene & 901 \\
\hline 374 & 1.28 & 2-Hexanone & 906 \\
\hline 378 & 1.18 & Pentanal & 876 \\
\hline 386 & 1.55 & 3-Ethyl-3-pentanol & 939 \\
\hline 446 & 2.16 & Dimethyl disulfide & 973 \\
\hline 478 & 1.89 & Toluene & 933 \\
\hline 478 & 2.98 & Pyridine & 968 \\
\hline 506 & 2.00 & 2-Methyl-3-heptanol & 876 \\
\hline 510 & 2.02 & Hexanal & 897 \\
\hline 566 & 2.26 & Methyl ethyl disulfide & 879 \\
\hline 578 & 1.22 & Butane & 863 \\
\hline 614 & 2.00 & Ethylbenzene & 940 \\
\hline 626 & 2.04 & 1,4-Dimethylbenzene & 960 \\
\hline 650 & 2.20 & 2-Heptanone & 972 \\
\hline 658 & 2.15 & Methyl propyl disulfide & 916 \\
\hline 666 & 2.16 & Heptanal & 902 \\
\hline 666 & 2.20 & 1,2-Dimethylbenzene & 895 \\
\hline 694 & 1.26 & Nonane & 931 \\
\hline 706 & 1.31 & 1-Decanol & 854 \\
\hline 750 & 1.24 & Decane & 878 \\
\hline 754 & 1.42 & $\alpha$-Pinene & 927 \\
\hline 762 & 2.02 & Benzaldehyde & 966 \\
\hline 766 & 1.91 & 2-Ethylhexanal & 931 \\
\hline 778 & 1.51 & Camphene & 874 \\
\hline 794 & 3.65 & Benzonitrile & 937 \\
\hline 822 & 1.28 & 3-Ethyloctane & 885 \\
\hline 826 & 2.24 & 2-Octanone & 940 \\
\hline 846 & 2.20 & Octanal & 943 \\
\hline 858 & 1.19 & Phenol & 874 \\
\hline 874 & 1.64 & $\alpha$-Phellandrene & 870 \\
\hline 894 & 2.39 & $1,3,5$-Trimethylbenzene & 934 \\
\hline 918 & 1.68 & Limonene & 929 \\
\hline 954 & 1.90 & Acetophenone & 937 \\
\hline 970 & 1.72 & $\alpha$-Terpinene & 910 \\
\hline
\end{tabular}

Table 1 (continued)

\begin{tabular}{llll}
\hline 1st RT/s & 2nd RT/s & Name of compounds & Similarity $^{\mathrm{a}}$ \\
\hline 978 & 2.09 & 1-Methyl-2-propylbenzene & 963 \\
1050 & 2.82 & 3-Pentanol & 865 \\
1234 & 3.88 & Benzothiazole & 897 \\
1514 & 1.46 & Acetic acid, decyl ester & 921
\end{tabular}

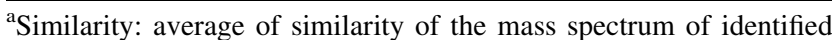
compounds to the spectra of standard compounds in the NIST 2011 library

Percentage contributions of chemical classes in the tested biosolid samples are presented in Table 2. It can be observed that sulfur compounds are dominant group of the chemical compounds in primary and dewatered sludge (28 and $25 \%$, respectively). In waste-activated sludge, aliphatic hydrocarbons, alcohols, and ketones are the most significant groups of chemical compounds. Dominant group of the chemical compounds in digested sludge is aliphatic hydrocarbons. Changes in the percentage contribution of chemical classes in various types of biosolids are strongly related to operation of WWTPs. During biological treatment, percentage contribution of sulfur compounds decreases, but sludge dewatering operation results in a significant increase in concentration of these compounds. Percentage contribution of aromatic hydrocarbons, which are one of the dominant groups of chemical compounds in the biosolid samples, is very similar for each type of sludge (from $12 \%$ in waste-activated sludge to $19 \%$ in dewatered sludge). Similarly, percentage contribution of alcohols does not change significantly during sludge treatment (from $16 \%$ in dewatered sludge to $21 \%$ in waste-activated sludge).

\section{Estimation of key odoriferous compounds emitted from biosolid cakes}

Table 3 presents surface area of the chromatographic peaks obtained for 20 chemical compounds, identified in volatile fraction of the investigated biosolid cakes, which have the biggest influence on the result of the performed statistical analysis. These compounds were divided into four chemical classes: alcohols, ketones, aromatic compounds, and organosulfur compounds, to find some dependences occurring within particular groups of the compounds. The statistical analysis revealed that each of the four types of biosolid cakes had different, statistically significant, composition of the volatile fraction. Significant differences 
Table 2 Percentage contributions of chemical classes in the tested biosolid samples

\begin{tabular}{lllll}
\hline Chemical classes & Primary sludge $(\%)$ & Waste-activated sludge $(\%)$ & Digested sludge $(\%)$ & Dewatered sludge $(\%)$ \\
\hline Sulfur compounds & 28 & 9 & 7 & 25 \\
Aromatic hydrocarbons & 16 & 12 & 14 & 19 \\
Aldehydes & 10 & 9 & 11 & 6 \\
Ketones & 9 & 20 & 11 & 9 \\
Aliphatic hydrocarbons & 9 & 20 & 25 & 16 \\
Alcohols & 19 & 21 & 18 & 16 \\
Others & 9 & 9 & 14 & 9 \\
\hline
\end{tabular}

Table 3 Differentiation between main VOCs emitted from biosolid samples; mean values $(n=3) \pm \mathrm{SD}$; different letters in the same line indicate significant differences among volatiles in each biosolid samples (Tukey's HSD test. $P<0.05)$

\begin{tabular}{|c|c|c|c|c|}
\hline \multirow[t]{2}{*}{ Chemical compound } & \multicolumn{4}{|c|}{ Chromatographic peak area/mean $\pm \mathrm{SD}\left(\times 10^{-3}\right)$} \\
\hline & $\mathrm{PS}^{\mathrm{a}}$ & WAS $^{\mathrm{a}}$ & $\mathrm{DGS}^{\mathrm{a}}$ & DWS $^{\mathrm{a}}$ \\
\hline \multicolumn{5}{|l|}{ Alcohols } \\
\hline 1-Decanol & $20.5 \pm 4.1$ & $18.5 \pm 3.8$ & $35.4 \pm 2.3$ & $34.5 \pm 1.6$ \\
\hline 2-Methyl-3-heptanol & $12.8 \pm 2.6^{\mathrm{a}, \mathrm{c}}$ & $46.1 \pm 4.8^{\mathrm{a}, \mathrm{d}, \mathrm{e}}$ & $11.5 \pm 1.5^{\mathrm{d}, \mathrm{f}}$ & $74.5 \pm 3.5^{\mathrm{c}, \mathrm{e}, \mathrm{f}}$ \\
\hline Ethanol & $47.4 \pm 2.7^{\mathrm{a}}$ & $851.1 \pm 23.2^{\mathrm{a}}$ & $11.0 \pm 1.0^{\mathrm{a}}$ & $231.8 \pm 2.7^{\mathrm{a}}$ \\
\hline 1-Propanol & $601.7 \pm 1.8^{\mathrm{a}}$ & $720.4 \pm 0.8^{\mathrm{a}}$ & $93.9 \pm 5.6^{\mathrm{a}}$ & $191.9 \pm 3.4^{\mathrm{a}}$ \\
\hline 3-Ethyl-3-pentanol & $14.2 \pm 1.2$ & $17.1 \pm 2.0$ & $16.3 \pm 1.1$ & $15.9 \pm 0.8$ \\
\hline \multicolumn{5}{|l|}{ Ketones } \\
\hline 2-Propanone & $46.7 \pm 2.3^{\mathrm{c}}$ & $47.7 \pm 3.3^{\mathrm{e}}$ & $47.2 \pm 1.2^{\mathrm{f}}$ & $177.1 \pm 6.0^{\mathrm{c}, \mathrm{e}, \mathrm{f}}$ \\
\hline Acetophenone & $263.1 \pm 15.1^{\mathrm{b}, \mathrm{c}}$ & $278.9 \pm 6.3^{\mathrm{d}, \mathrm{e}}$ & $64.9 \pm 2.6^{\mathrm{b}, \mathrm{d}, \mathrm{f}}$ & $19.8 \pm 1.6^{\mathrm{c}, \mathrm{e}, \mathrm{f}}$ \\
\hline 2-Hexanone & $787.3 \pm 5.2^{\mathrm{a}}$ & $830.9 \pm 3.0^{\mathrm{a}}$ & $55.3 \pm 2.5^{\mathrm{a}}$ & $86.8 \pm 1.4^{\mathrm{a}}$ \\
\hline 2-Heptanone & $20.5 \pm 1.0^{\mathrm{b}}$ & $12.6 \pm 2.1^{\mathrm{d}}$ & $72.3 \pm 4.7^{\text {b.d.f }}$ & $22.4 \pm 2.7^{\mathrm{f}}$ \\
\hline 2-Octanone & $47.1 \pm 1.7^{\mathrm{a}}$ & $26.8 \pm 2.2^{\mathrm{a}}$ & $44.4 \pm 2.3$ & $30.6 \pm 0.9$ \\
\hline \multicolumn{5}{|l|}{ Aromatic compounds } \\
\hline Benzene & $884.6 \pm 10.5^{\mathrm{a}, \mathrm{b}}$ & $930.7 \pm 6.9^{\mathrm{a}, \mathrm{d}, \mathrm{e}}$ & $906.0 \pm 1.3^{\mathrm{b}, \mathrm{d}}$ & $890.9 \pm 6.8^{\mathrm{e}}$ \\
\hline 1.3.5-Trimethylbenzene & $21.3 \pm 2.3^{\mathrm{c}}$ & $6.9 \pm 0.5^{\mathrm{e}}$ & $14.7 \pm 2.0^{\mathrm{f}}$ & $89.8 \pm 1.8^{\mathrm{c}, \mathrm{e}, \mathrm{f}}$ \\
\hline$o$-Xylene & $69.1 \pm 0.8^{\mathrm{b}, \mathrm{c}}$ & $68.1 \pm 1.0^{\mathrm{d}, \mathrm{e}}$ & $152.5 \pm 6.0^{\mathrm{b}, \mathrm{d}, \mathrm{f}}$ & $190.5 \pm 8.4^{\mathrm{c}, \mathrm{e}, \mathrm{f}}$ \\
\hline$p$-Xylene & $51.2 \pm 4.2^{\mathrm{b}}$ & $45.8 \pm 2.9^{\mathrm{d}}$ & $172.8 \pm 4.4^{\mathrm{b}, \mathrm{d}, \mathrm{f}}$ & $37.0 \pm 3.0^{\mathrm{f}}$ \\
\hline Toluene & $85.0 \pm 1.4^{\mathrm{b}, \mathrm{c}}$ & $66.2 \pm 2.5^{\mathrm{d}, \mathrm{e}}$ & $199.4 \pm 2.6^{\mathrm{b}, \mathrm{d}, \mathrm{f}}$ & $750.9 \pm 1.8^{\mathrm{c}, \mathrm{e}, \mathrm{f}}$ \\
\hline \multicolumn{5}{|l|}{ Sulfur compounds } \\
\hline Ethanethiol & $963.6 \pm 7.0^{\mathrm{a}}$ & $53.6 \pm 0.2^{\mathrm{a}}$ & $653.1 \pm 5.5^{\mathrm{a}}$ & $545.8 \pm 1.3^{\mathrm{a}}$ \\
\hline Dimethyl sulfide & $43.9 \pm 2.2^{\mathrm{a}}$ & $14.9 \pm 1.7^{\mathrm{a}}$ & $222.9 \pm 3.9^{\mathrm{a}}$ & $650.8 \pm 2.1^{\mathrm{a}}$ \\
\hline Dimethyl disulfide & $99.4 \pm 3.9^{\mathrm{a}}$ & $23.6 \pm 2.1^{\mathrm{a}}$ & $893.4 \pm 5.5^{\mathrm{a}}$ & $248.0 \pm 0.4^{\mathrm{a}}$ \\
\hline Diethyl disulfide & $13.0 \pm 1.2^{\mathrm{b}, \mathrm{c}}$ & $7.5 \pm 0.9^{\mathrm{d}, \mathrm{e}}$ & $768.6 \pm 1.8^{\mathrm{b}, \mathrm{d}, \mathrm{f}}$ & $985.5 \pm 4.7^{\mathrm{c}, \mathrm{e}, \mathrm{f}}$ \\
\hline Methanethiol & $2888.8 \pm 4.8^{\mathrm{a}}$ & $90.7 \pm 1.2^{\mathrm{a}}$ & $110.9 \pm 1.9^{\mathrm{a}}$ & $771.4 \pm 1.8^{\mathrm{a}}$ \\
\hline
\end{tabular}

${ }^{\mathrm{a}}$ Differences between PS and WAS

${ }^{\mathrm{b}}$ Differences between PS and DGS

${ }^{c}$ Differences between PS and DWS

${ }^{\mathrm{d}}$ Differences between WAS and DGS

${ }^{\mathrm{e}}$ Differences between WAS and DWS

${ }^{\mathrm{f}}$ Differences between DGS and DWS 
among volatiles in each biosolid sample were indicated using small letter:

- The letter "a" indicates significant differences between primary sludge and waste-activated sludge (PS-WAS);

- The letter "b" indicates significant differences between primary sludge and digested sludge (PS-DGS);

- The letter "c" indicates significant differences between primary sludge and dewatered sludge (PS-DWS);

- The letter "d" indicates significant differences between waste-activated sludge and digested sludge (WASDGS);

- The letter "e" indicates significant differences between waste-activated sludge and dewatered sludge (WASDWS);

- The letter "f" indicates significant differences between digested sludge and dewatered sludge (DGS-DWS).

The letter "a" located within the same line indicates significant differences between all four types of biosolid samples.

Based on the data presented in Table 3, it can be stated that, within the chemical class of alcohols, only two compounds (ethanol and 1-propanol) exhibited statistically significant differences in composition of volatile fraction of the investigated biosolid cakes. 1-Propanol was proposed as a potential marker, because the presence of ethanol can result from numerous processes and operations, conducted not only in the wastewater treatment plants. 1-Propanol is one of the most frequently identified alcohols released from the biosolid cakes [24]. 2-Hexanone can be proposed as a potential marker from the ketones' group. Similar to 1-propanol, it can be the marker allowing differentiation between various biosolid cakes.

In case of the statistical analysis of aromatic hydrocarbons, it is difficult to point a single compound, which could be a potential marker for biosolid cake differentiation. Toluene is the compound, which makes it possible to discriminate almost all investigated biosolid cakes-an exception is differentiation between primary and excess biosolid cakes, in which content of this substance is similar. Analogous situation occurs for the isomers of $o$-xylene and $p$-xylene. However, differentiation between primary and excess biosolid cakes is possible with benzene. It is worth emphasizing that the papers concerning measurement of the compounds emitted from the wastewater treatment plants show that toluene as well as isomers of xylene are the compounds characteristic for biosolid cake processing [24, 26].

The last group included in Table 3 is organosulfur compounds. Many papers on investigation of the biosolid cakes found these substances as key ones [25, 27, 28]. Performed statistical analysis revealed that methanethiol and ethanethiol could be the potential markers of particular types of the biosolid cakes. This statement is supported by the fact that remaining three compounds from the organosulfur group allow discrimination of most biosolid cakes, except for primary and excess ones.

Table 4 gathers concentrations of the odoriferous compounds, which were proposed, based on the statistical analysis, as potential markers of four types of biosolid cakes. Analysis of these data indicates that organosulfur compounds are characterized by relatively low concentrations as compared to the remaining compounds released from the biosolid cakes, especially in case of the excess cake. It can be also observed that the biosolid cakes after fermentation process exhibit higher content of organosulfur compounds than the excess cake. Literature explains this phenomenon by the fact that protein amino acids (for instance methionine), responsible for the production of organosulfur compounds in anaerobic conditions, are

Table 4 Concentration of key chemical compounds emitted from biosolid samples

\begin{tabular}{|c|c|c|c|c|c|c|}
\hline \multirow[t]{2}{*}{ Chemical compound } & \multicolumn{4}{|l|}{$\mathrm{C} \pm \mathrm{SD} / \mathrm{ppb}$} & \multirow[t]{2}{*}{ Odour description } & \multirow[t]{2}{*}{$\mathrm{OT} / \mathrm{ppb}[31]$} \\
\hline & PS & WAS & DGS & DWS & & \\
\hline 1-Propanol & $23.0 \pm 1.2$ & $28.2 \pm 1.3$ & $3.9 \pm 0.2$ & $74.1 \pm 2.9$ & Alcoholic, fruity, musty, pungent & 94.0 \\
\hline 2-Hexanone & $19.5 \pm 0.9$ & $20.7 \pm 1.1$ & $1.4 \pm 0.2$ & $2.2 \pm 0.1$ & Ethereal, fruity, cinnamon & 24.0 \\
\hline$o$-Xylene & $15.8 \pm 0.7$ & $15.6 \pm 0.6$ & $34.9 \pm 1.7$ & $43.7 \pm 2.1$ & Fatty, geranium, oily, pungent & 380.0 \\
\hline$p$-Xylene & $11.7 \pm 0.7$ & $10.3 \pm 0.5$ & $39.5 \pm 1.2$ & $8.5 \pm 0.4$ & Cold meat fat, sweet & 58.0 \\
\hline Toluene & $2.2 \pm 0.1$ & $1.7 \pm 0.3$ & $5.2 \pm 0.3$ & $19.5 \pm 0.9$ & Ethereal, pungent, rubber, solvent, & 330.0 \\
\hline Ethanethiol & $3.7 \pm 0.8$ & $1.1 \pm 0.1$ & $2.5 \pm 0.1$ & $2.2 \pm 0.1$ & Garlic-like, skunk-like, strong & 0.0087 \\
\hline Dimethyl sulfide & $1.6 \pm 0.2$ & $0.5 \pm 0.1$ & $8.5 \pm 0.3$ & $25.1 \pm 1.5$ & Cabbage, mouldy, sulfurous & 3.0 \\
\hline Dimethyl disulfide & $2.5 \pm 0.3$ & $0.6 \pm 0.1$ & $22.7 \pm 1.3$ & $6.3 \pm 0.7$ & Cabbage, onion, sulfurous, putrid & 2.2 \\
\hline Diethyl disulfide & $0.3 \pm 0.1$ & $1.5 \pm 0.1$ & $15.1 \pm 1.3$ & $19.4 \pm 1.7$ & Poultry, cabbage, brussels sprout & 2.0 \\
\hline Methanethiol & $14.4 \pm 1.0$ & $0.5 \pm 0.1$ & $0.6 \pm 0.1$ & $3.9 \pm 0.2$ & Cabbage, rotten egg, sulfurous & 0.07 \\
\hline
\end{tabular}


relatively durable and they do not undergo degradation [27, 29].

Seven out of ten chemical compounds emitted from the biosolid cakes (presented in Table 3) reveal higher concentration in dewatered cake than in fermented cake. It can be caused by a rapid growth of bacteria following cake dewatering, especially when this process is carried out in centrifuges (these devices are used in the treatment plants, from which the investigated samples of biosolid cakes were collected) [30].

Substantial differences were observed upon comparison of the results of VOCs emission from dewatered biosolid cakes originating from the treatment plants with different systems of water removal. One of them concerned aromatic hydrocarbons content in dewatered biosolid cakes-the cakes dewatered in a mechanical way using the centrifuges were richer in aromatic hydrocarbons than gravitationally dewatered cakes [24]. Another factors, which can have an influence on emission level of particular compounds from dewatered biosolid cakes, are the parameters of fermentation process (temperature and retention time) and, in the case of cake dewatering, amount of added flocculant, which facilitates separation of solid particles from liquid fraction via participation in aggregates' formation [29].

Table 4 also presents the values of olfactory threshold (OT), together with odour description. Olfactory threshold is the lowest concentration of each substance, which causes sensing of the smell with $50 \%$ probability. These data were used to determine theoretical odour concentrations for each of the four investigated types of biosolid cakes. The theoretical odour concentrations were calculated as a ratio of concentration of particular compound to its olfactory threshold. Figure 1 illustrates the results obtained in this way. The highest value of $c_{o d}$ was obtained for the primary cake, whereas the lowest one was for the excess cake. This situation is connected primarily with the concentration level of organosulfur compounds in these two types of biosolid cakes. Much higher content of those compounds is in the primary cake. Organosulfur compounds reveal very

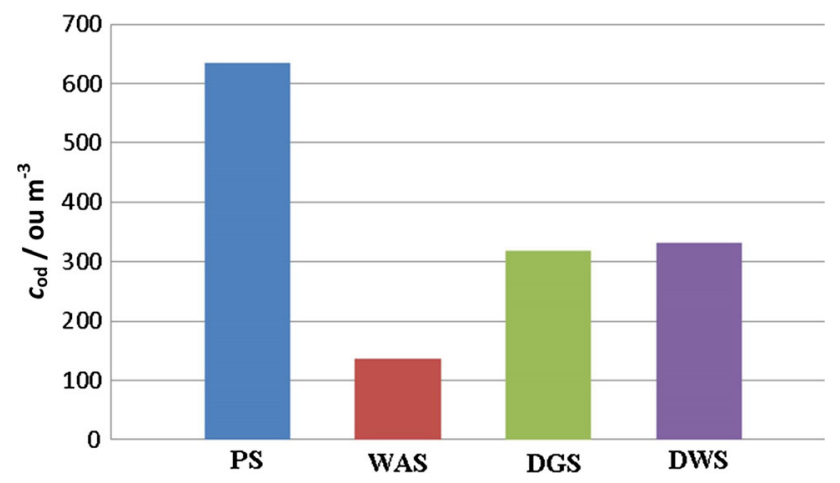

Fig. 1 Odor concentration of biosolid samples low values of olfactory threshold; hence, their contribution to strength of perceived odour is decisive. It is also the reason why dewatered cake exhibits higher odour concentration than fermented cake. One of the problems connected with the determination of concentration of organosulfur compounds emitted from the biosolid cakes is their instability. In the case of application of the solid sorbent-filled tubes, these compounds are released due to thermal desorption (at ca. $250-300{ }^{\circ} \mathrm{C}$ ). At this temperature, thiols can be converted into sulfides. When thiols are present below LOD, it is reasonable to take advantage of summary concentration of organosulfur compounds not to omit contribution of such compounds as methanethiol or ethanethiol to strength of perceived odour [30, 32]. However, this approach hinders determination of the contribution of particular odorants because of different values of olfactory threshold.

\section{Conclusions}

Application of the methodology proposed in this paper, based on the GCxGC-TOF-MS technique and statistical analysis, allowed the determination of concentration of the volatile organic compounds, which could be potential markers for differentiation between four main types of biosolid cakes. Employed procedure was much less timeconsuming mainly due to no need for quantitative analysis of all identified compounds, which in the case of gas samples is usually long and laborious step. Two-dimensional gas chromatography coupled with time-of-flight mass spectrometry technique makes it possible to define chemical composition of the samples with complex matrix, including such biological samples as the biosolid cakes. Utilization of numerical values of olfactory thresholds allows assessment of perceived odour strength of the biosolid cake samples, without olfactometric analyses. A disadvantage of the olfactometric approach is a need for team of trained assessors and suitable laboratory. The methodology presented in the paper can be an alternative to the existing solutions in the field of measurement of VOCs' emission level from the biosolid cakes.

\section{Experimental}

\section{Biosolid sample collection}

The biosolid samples were collected from the WWTP "Debogórze" located in Pomeranian Voivodeship, Poland. This facility is one of the biggest plants in this region and consists of three main technological sections: mechanical section, biological section, and sludge treatment 
section. Each day, $55,000 \mathrm{~m}^{3}$ of sewage are supplied to this facility, 1.5 tons of waste are produced during mechanical treatment, and 31 tons of solid sludge are generated.

Four biosolid samples (primary sludge-PS; waste-activated sludge-WAS; digested sludge-DGS; and dewatered sludge-DWS) were collected in $20 \mathrm{dm}^{3}$ buckets and directly transported to a laboratory at the Gdansk University of Technology. Before measurements, the biosolid samples were stored at ambient conditions.

\section{Instrumentation}

To generate emission from the biosolid samples, the US EPA flux hood chamber was used. This device is widely utilized for identification of the chemical compounds emitted from various types of surfaces. Before each measurement, the biosolid samples were purged for $30 \mathrm{~min}$ using nitrogen gas with the flow rate $5 \mathrm{dm}^{3} / \mathrm{min}$. The VOCs samples were collected for 10 min using the Tenax TA sorbent tubes (Gerstel, Germany), with the sampling flow rate $75 \mathrm{~cm}^{3} / \mathrm{min}$.

The chemical compounds emitted from the biosolid samples were determined using two-dimensional gas chromatography (Agilent Technologies, Palo Alto, CA, USA) equipped with a liquid nitrogen-based dual-stage cryogenic modulator and coupled with Pegasus IV time-offlight mass spectrometer (LECO Corp., St. Joseph, MI, USA). Equity 1 capillary column $(30 \mathrm{~m} \times 0.25 \mathrm{~mm} \times$ $0.25 \mu \mathrm{m}$ film, Supelco) was used as a primary column; SGWAX capillary column $(2.0 \mathrm{~m} \times 0.1 \mathrm{~mm} \times 0.1 \mu \mathrm{m}$ film, Agilent Technologies) was used as the second column. A modulation period of $5 \mathrm{~s}$ was employed. To separate all chemical components present in the samples, the following optimized temperature program was used: for the first GC oven: initial temperature of $40{ }^{\circ} \mathrm{C}$ maintained for $1 \mathrm{~min}$, then ramped at $10{ }^{\circ} \mathrm{C} / \mathrm{min}-90{ }^{\circ} \mathrm{C}$ and at $3{ }^{\circ} \mathrm{C} / \mathrm{min}-$ $240{ }^{\circ} \mathrm{C}$, and, finally, kept constant for $5 \mathrm{~min}$; for the secondary GC oven, the optimized temperature program was with the shift of $+5{ }^{\circ} \mathrm{C}$ regarding the program of the primary GC oven. Hydrogen at a constant flow rate $1 \mathrm{~cm}^{3} /$ min was used as a carrier gas. The total analysis time was $45 \mathrm{~min}$. Ions in the $\mathrm{m} / \mathrm{z}=40-500$ range were analysed. The detector voltage was set to $1600 \mathrm{~V}$ and the temperature of the ion sources and the transfer line were maintained at $250{ }^{\circ} \mathrm{C}$.

\section{Data analysis}

Analysis of the data obtained with the GCxGC-TOF-MS system was performed using the algorithm for peak deconvolution (with signal-to-noise setup at 100), included in the Chroma TOF software (LECO Corp., USA, version 4.44) Tentative identification was accomplished based on the selected fragmentation ions listed in the NIST 2011 Mass Spectral Library v. 2.0).

\section{Statistical analysis}

To determine the differences between volatile compounds emitted from various types of biosolids samples, two-way analysis of variance (ANOVA) was performed. Tukey's honest significant difference test (HSD Tukey's test, $p<0.05)$ was applied to compare the mean values of VOCs for different types of biosolid samples. The analysis was carried out using STATISTICA 12 software (StatSoft, Inc., Tulsa, Oklahoma, USA). Mean values and standard deviation (SD) were calculated from three repetitions for each biosolid sample.

Open Access This article is distributed under the terms of the Creative Commons Attribution 4.0 International License (http://creative commons.org/licenses/by/4.0/), which permits unrestricted use, distribution, and reproduction in any medium, provided you give appropriate credit to the original author(s) and the source, provide a link to the Creative Commons license, and indicate if changes were made.

\section{References}

1. Cieślik BM, Namieśnik J, Konieczka P (2015) J Clean Prod 90:1

2. Wu C, Liu J, Zhao P, Li W, Yan L, Piringer M, Schauberger G (2017) Atmos Environ 164:337

3. Yan L, Liu J, Jiang S, Wu C, Gao K (2017) Sensors 17:1624

4. Garrido-Baserba M, Molinos-Senante M, Abelleira-Pereira JM, Fdez-Güelfo LA, Poch M, Hernández-Sancho F (2015) J Clean Prod 107:410

5. Beghia SP, Rodriguesa AC, de Sa LM, Santosa JM (2012) Chem Eng Trans 30:91

6. Gębicki J, Byliński H, Namieśnik J (2016) Environ Monit Assess 188:32

7. Cieślik B, Konieczka P (2016) Arch Waste Manag Environ Prot 18:15

8. Chen WH, Lin SJ, Lee FC, Chen MH, Yeh TY, Kao CM (2017) Proc Saf Environ Prot 109:410

9. González-Cebrino F, García-Parra J, Ramírez R (2016) Innov Food Sci Emerg Techn 33:108

10. Siti HN, Kamisah Y, Nur Iliyani MI, Mohamed S, Jaarin K (2017) Biomed Pharm 87:451

11. Marsol-Vall A, Balcells M, Eras J, Canela-Garayoa R (2018) Food Chem 239:119

12. Błaszczak W, Amarowicz R, Górecki AR (2017) Innov Food Sci Emerg Technol 39:141

13. Hudson N, Gies A, Duperouzel D (2006) Biores Techn 97:2015

14. Klenbusch MR (1986) User's guide EPA-600/8-86/008. US Environmental Protection Agency, Washington, DC

15. Hudson N, Ayoko GA, Dunlop M, Duperouzel D, Burrell D, Bell K, Gallagher E, Nicholas P, Heinrich N (2009) Biores Technol 100:118

16. Wiergowski M, Woźniak MK, Kata M, Biziuk M (2016) Monatsh Chem 147:1415

17. Kosek K, Kozak K, Kozioł K, Jankowska K, Chmiel S, Polkowska Ż (2018) Sci Total Environ 622-623:913 
18. Brasseur C, Dekeirsschieter J, Schotsmans EMJ, de Koning S, Wilson AS, Haubruge E, Focant JF (2012) J Chrom A 1255:163

19. Perrault KA, Rai T, Stuart BH, Forbes SL (2015) Anal Methods 7:690

20. Almstetter MF, Oefner PJ, Dettmer K (2012) Anal Bioanal Chem 402:1993

21. Marriott PJ, Chin ST, Maikhunthod B, Schmarr HG, Bieri S (2012) Trends Anal Chem 34:1

22. Byliński H, Kolasińska P, Dymerski T, Gębicki J, Namieśnik J (2017) Monatsh Chem 148:1651

23. Rosenfeld PE, Henry CL, Dills RL, Harrison RB (2001) Water Air Soil Pol 127:173

24. Fisher RM, Le-Minh N, Sivret EC, Alvarez-Gaitan JP, Moore SJ, Stuetz RM (2017) Sci Total Environ 599-600:663
25. Lehtinen J, Veijanen A (2011) Water Air Soil Pol 218:185

26. Fatone F, Di Fabio S, Bolzonella D, Cecchi F (2011) Water Res 45:93

27. Fisher RM, Alvarez-Gaitan JP, Stuetz RM, Moore SJ (2017) J Environ Manag 198:153

28. Novak JT, Sadler ME, Murthy SN (2003) Water Res 37:3136

29. Kacker R, Novak JT, Higgins MJ (2011) Proc Water Environ Fed 9:6409

30. Chen YC, Higgins MJ, Beightol SM, Murthy SN, Toffey WE (2011) Water Res 45:2616

31. Nagata Y (2003) Odor Measur Rev:118

32. Fisher RM, Le-Minh N, Alvarez-Gaitan JP, Moore SJ, Stuetz RM (2018) Sci Total Environ 616-617:622 